in each participating institution is essentially loaded by the institution's coordinator to ensure relevance and a reasonable level of homogeneity. It can be consulted over Internet by telneting to emspsdb.man.ac.uk (logon = "student"; password = "student1"). The committee decided to convert the information to make it available on the World-Wide Web (WWW). This process has started and the EMSPS database together with all the information and documents relating to the scheme can now be accessed at http://info.mcc.ac.uk/emsps/. Links to other WWW servers giving general information on mobility arrangements in participating institutions are envisaged. Only time will tell if a more decentralized structure is desirable.

The EMSPS service is coordinated by the EPS Internet Coordination Group as part of the EPS EurophysNet network of linked WWW servers covering all EPS activities. So it can be linked to via the EurophysNet home page at http://epswww.epfl.ch. However, WWW access is by no means universal and even telnet access is rare in some EMSPS institutions. Coordinators are obviously working to improve the situation. It is envisaged that the telnet service will be maintained for another 18 months while information is converted.

The committee has also been collaborating with the new EPS Interdivisional Group for Physics Education on the much wider issue of ways to improve physics education in Europe. One opportunity is to establish a European Physics Education Network (EUPEN) to support a European dimension through cooperation between university departments. A steering committee (H. Ferdinande, C.M. Ferreira, L. Dona'dalle Rose, J.C. Dore, and E. Elbaz with I. Sosnowska as an associate) is to submit a funding application by 1 January 1996 to SOCRATES that will be based on the outcome of last April's EC thematic evaluation conference [EN 26 (1995) 69].

Thanks to the indefatigable R.G.H. Greer who hosted the meeting, the Committee was able to tackle a very charged agenda while enjoying several different locations interspersed with special events. The latter included a reception organized by Belfast's City Council in its City Hall and a meeting with four students from France, Austria and Poland who were starting their mobility year at The Queen's University.

\section{Condensed Matter Division Board} CALL FOR NOMINATIONS

The Board of the EPS Condensed Matter Division includes five members elected by Individual Ordinary Members (IOMs) of EPS who belong to the Division. These IOMs are invited to submit by 30 November 1995 the names of candidates for election to the Division Board. Nominations should be sent to G. Thomas, Secretary General, EPS, BP $69, \mathrm{CH}-1213$ Petit-Lancy 2 (fax: $+41-22-793$ 13 17). Three supporting signatures of IOMs are required as well as a candidate's written agreement that he or she is willing to serve. The term of office is three years and re-election for a second period is allowed.

J.L. Beeby, S. Hess and I. Ipatova will stand for re-election so an additional two nominations are sought.

\title{
Remembering Gilberto Bernardini
}

\author{
Gilberto Bernardini, the first EPS President, left us on August 4 of this year while \\ living in his beloved Florence where he was born in 1906.
}

"... We do believe, then, that Europe is the country that has the best chances of bringing a fundamental contribution to the creation of this new approach to the life where science will represent a new humanism for the structure of societies, as well as for the comfort of individuals. The European Physical Society, according to us, should be formed into these hopes."

It was with these words that Gilberto Bernardini ended his speech at the ceremony held in the University of Geneva's Aula Magna on 26 September 1968 marking the foundation of EPS.

His message culminated the realisation of the dream that Gilberto spoke of for the first time at the National Conference of the Italian Physical Society in November 1965 in Bologna. This dream was defined and articulated three years later in Pisa in the spring of 1968 following the creation, at the end of 1967, of a steering committee to draw up the first EPS Constitution.

As Bernardini recalled in 1988 when we celebrated in Pisa the 20th anniversary of the foundation of EPS, the Society's creation was a "milestone of the future European nation ...." - nation that he and the founding fathers had in mind for the physics community throughout Europe, both east and west. This "universal spirit" was present in Florence at the EPS Inaugural Conference held in April 1969 at the Palazzo Vecchio with Bernardini, as the EPS President (1968-1970), in the chair. It was present 24 years later in Florence at the 9th EPS General Conference and celebration of the 25th EPS anniversary, where he made one of his last public appearances.

Before becoming President of EPS, Gilberto was from 1961 to 1967 the second President of the Italian Physical Society. He always represented an exceptional point of reference, both as a scientist and as a human being, in developing and strengthening the unity and cultural development of physics in Italy and in Europe. With him a truly historical era disappears, since he belonged to the group of founding fathers to which we owe the renaissance of physics research in Italy in the 1950s after the Second World War. Its members tackled a challenge that let Amaldi, Bernardini, Occhialini, and Rostagni among others, together with Polvani, the first President of the Italian Physical Society, assume the inheritance of Enrico Fermi and Bruno Rossi who worked in Rome and in Florence in the 1930s.

It was in fact near Florence (in Arcetri) that Gilberto met Bruno Rossi in 1928. Let's quote Rossi himself from "Early Days in Cosmic Rays" [Physics Today, October 1981]: “... The group I found in Arcetri was quite small, but quality made up for the size. Gilberto Bernardini, a recent $P h D$ in physics from the University of Pisa, had joined the group before my arrival. Among the

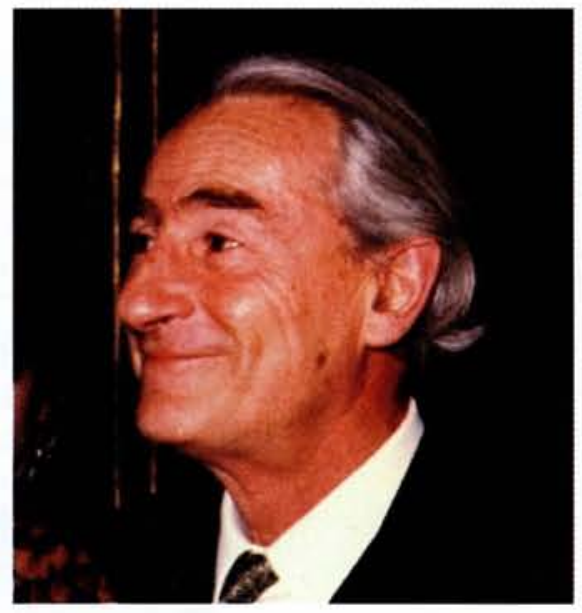

Gilberto Bernardini in April 1968 at the EPS Inaugural Conference.

students were Guiseppe Occhialini, Giulio Racah, Daria Bucciarello, Guglielmo Righini, Lorenzo Emo... Both Bernardini and I were very anxious to start some experimental program ...."

It is this tradition which enabled Gilberto, after his research in the United States (Columbia, Urbana and Chicago), to contribute personally and enormously to the evolution of cosmic-ray and elementary particle physics in Italy in the 1940s with the realisation of the "Testa Grigia" laboratory on Monte Cervino in 1942. It was the first European high-altitude laboratory dedicated to detecting cosmic rays. Moreover, Gilberto Bernardini, together with Edoardo Amaldi, was one of the founders of the National Institute for Nuclear Physics (the INFN). He served as the organization's first President from 1954 to 1961 while contributing to the foundation of CERN, where he was Director, initially of the Synchro-Cyclotron (SC) Division and subsequently of the Research Division. His Presidency of the INFN saw the creation of the National Laboratory of Frascati with its $1000 \mathrm{MeV}$ electrosynchrotron which was for some time Italy's principle research instrument. This step allowed Italian physicists to work once again at the frontiers of nuclear and sub-nuclear physics and of the related studies on fundamental interactions.

Last September's meeting on "Astrophysics and Cosmic Rays" held in Florence to honour Occhialini, Pontecorvo and Rossi - three of Italy's most eminent physicists should have been opened by Bernardini. Unfortunately for us he could not attend. Now he has joined them for ever in our memory. And together with them he leaves us, as his precious heritage and his most edifying example, not only his scientific stature but also his inspiring humanity.

R.A. Ricci

President, Italian Physical Society EPS Past-President 